\title{
Local Population Structure in Arabian Peninsula Revealed by Y-STR Diversity
}

\author{
Farida Alshamali $^{\mathrm{a}}$ Luísa Pereira $^{\mathrm{b}, \mathrm{c}}$ Bruce Budowle $^{\mathrm{d}}$ Estella S. Poloni ${ }^{\mathrm{e}}$ \\ Mathias Currat ${ }^{\mathrm{e}}$

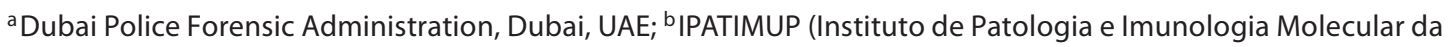 \\ Universidade do Porto), and ' ${ }^{\mathrm{C}}$ Medical Faculty, University of Porto, Porto, Portugal; ${ }^{\mathrm{d}}$ Federal Bureau of Investigation, \\ Laboratory Division, Quantico, Va., USA, and 'Laboratoire d'Anthropologie, Génétique et Peuplements (AGP), \\ Département d'Anthropologie et Ecologie, Université de Genève, Carouge, Switzerland
}

Key Words

Y-STR $\cdot$ Population structure $\cdot$ Arabian Peninsula

\begin{abstract}
Genetic studies have been underway on Arabian Peninsula populations because of their pivotal geographic location for population migration and times of occurrence. To assist in better understanding population dynamics in this region, evidence is presented herein on local population structure in the Arabian Peninsula, based on Y-STR characterisation in four Arabian samples and its comparison in a broad geographical scale. Our results demonstrate that geography played an important role in shaping the genetic structure of the region around the Near-East. Populations are grouped regionally but none of these groups is significantly differentiated from others and all groups merge in the Near-East, in keeping with this important migration corridor for the human species. Focusing on the Arabian Peninsula, we show that Dubai and Oman share genetic affinities with other Near-Eastern populations, while Saudi Arabia and Yemen show a relative distinctive isolated background. Those two populations may have been kept relatively separated from migration routes, maybe due to their location in a desert area.

Copyright $\odot 2009$ S. Karger AG, Basel
\end{abstract}

\section{Introduction}

Investigations in population genetics and archaeology are focusing on the Arabian Peninsula, because of its central geographical location for current models of modern human evolution, such as the Out-of-Africa migration of modern humans, the Neolithic emergence and dispersion, prehistoric contacts between East Asian, African and Eurasian cultures and people, the slave trade from Africa, and the Islamic expansion. Lineage marker based population studies, such as those undertaken with mitochondrial DNA (mtDNA) sequences [see 1 for a review], have been used to refine the Out-of-Africa model, favouring a possible southern route of migration, from the Horn of Africa, through the south of the Arabian Peninsula, to south India, southeast Asia and Australasia [2, 3]. However, data obtained so far on specific Arabian populations are somewhat contradictory, some now indicating only a minor African influence in Saudi Arabia [4], Yemen [5, 6] and Dubai [7]. Moreover, slave trade has been proposed as the major cause for sub-Saharan mtDNA haplogroups in Arabian populations [8].

The male genetic lineage history is not necessarily coincident with the female one. Richards et al. [8] showed that the sub-Saharan male input in Arab populations was less important than that of the female component of the population, with Y-chromosome haplogroup E3a-M2 at-

Luísa Pereir

IPATIMUP

R. Dr. Roberto Frias $\mathrm{s} / \mathrm{n}$

PT-4200-465 Porto (Portugal)

Tel. +35122557 0700, Fax +35122557 0799, E-Mail lpereira@ipatimup.pt

\section{1-5652/09/0681-0045\$26.00/0}

Accessible online at:

www.karger.com/hhe 
taining a maximum frequency of $4 \%$ in Yemen Hadramawt. More recently, Luis et al. [9] detected 7\% of this same haplogroup and its derivatives in Oman, and a similar frequency in Egypt, and they also concluded that the presence of this haplogroup was the result of the slave trade. However, the main conclusion in that study was a greater affinity of Egypt and Oman with the Middle East than with sub-Saharan Africa, which supports a major role of the Neolithic expansion from the Middle East through the Levantine route. This predominant Near Eastern Neolithic background in Egypt is shared with the rest of North Africa [10].

While Y Single Nucleotide Polymorphisms (SNPs) are also used in evolutionary studies, the Y Short Tandem Repeats (STRs) have provided some insights, such as through the estimation of the coalescence time of a particular haplogroup [10]. It has been shown that Y-SNP and Y-STR demographic inferences were not concordant at a European scale [11] and at a worldwide scale [12]. The Y SNPs did not show signs of population expansion while the Y STRs did, similarly to what was observed for mtDNA. These contradictory results could be due to an ascertainment bias where typing only highly frequent SNPs could erase the signature of population expansion [13]. In fact, Y-STR haplotypes were informative in discerning recent events, such as the western and eastern Bantu waves of migration towards Southern Africa, within the last 3,000 years [14]. Additionally, the power of YSTRs was demonstrated in detecting signatures of historical events, at a European scale [15], even between neighbouring countries such as Germany and Poland [16]. Roewer et al. [15] recommended that, notwithstanding the uncertainty in ascertaining a recent or prehistoric origin for a genetic pattern on the basis of Y-STR analyses alone, these markers should be the choice for studies on local population structure and recent demographic history. Due to high success in forensic genetic identity testing applications, there is substantial population data on Y-STR diversity, and a practical and functional database has been developed [17].

To add another dimension to the whole-scale genetic study of the Arabian Peninsula, we describe Y chromosome diversity in five populations (Saudi Arabia, Oman, Dubai in the United Arab Emirates, Yemen and the South of Iran) with 7 Y-STR loci (DYS19, DYS389I, DYS389II, DYS390, DYS391, DYS392 and DYS393). Our analyses, and those of published data cover the Arabian Peninsula and neighbouring areas, revealed a genetic structure in the Peninsula, differentiating notably Saudi Arabia and Yemen.
Table 1. Populations used in analyses, number of individuals surveyed, and number of haplotypes (the ones without duplications at any locus) studied herein. Each haplotype was comprised of the following loci: DYS19-DYS389I-DYS389II-DYS390-DYS391DYS392-DYS393

\begin{tabular}{|c|c|c|c|}
\hline & $\begin{array}{l}\text { Sample } \\
\text { size }^{\mathrm{a}}\end{array}$ & $\begin{array}{l}\text { Number of chro- } \\
\text { mosomes without } \\
\text { duplications } s^{\mathrm{b}}\end{array}$ & Ref. \\
\hline \multicolumn{4}{|l|}{ Arabian Peninsula } \\
\hline Dubai & 217 & 216 & this work \\
\hline Oman & 99 & 99 & this work \\
\hline Yemen & 104 & 103 & this work \\
\hline Saudi Arabia & 106 & 106 & this work \\
\hline \multicolumn{4}{|l|}{ North and East Africa } \\
\hline Morocco (Arabs) & 60 & 60 & 33 \\
\hline Tunisia & 134 & 134 & 10 \\
\hline Egypt & 83 & 83 & $34^{\mathrm{c}}$ \\
\hline North Egypt & 47 & 47 & 10 \\
\hline Ethiopia & 173 & 173 & YHRD \\
\hline \multicolumn{4}{|l|}{ Middle East } \\
\hline Damascus-Syria & 100 & 100 & $17^{\mathrm{c}}$ \\
\hline Syria & 113 & 113 & $35^{c}$ \\
\hline Kurds & 126 & 126 & $36^{c}$ \\
\hline Iran-South & 104 & 103 & this work \\
\hline Iran-Tehran and Isfahan & 128 & 128 & 37 \\
\hline \multicolumn{4}{|l|}{ Caucasus and Turkey } \\
\hline North Caucasus & 239 & 239 & 37 \\
\hline Armenia & 100 & 99 & 37 \\
\hline Azerbaijan & 72 & 72 & 37 \\
\hline Georgia & 77 & 77 & 37 \\
\hline Turkey & 113 & 110 & 38 \\
\hline Turkey-other & 158 & 158 & $39^{c}$ \\
\hline \multicolumn{4}{|l|}{ Southeastern Europe } \\
\hline Romania & 104 & 102 & 40 \\
\hline Bosnia-Herzegovinia & 181 & 181 & 41 \\
\hline Serbia & 114 & 114 & 42 \\
\hline Croatia & 101 & 101 & 43 \\
\hline Albania & 101 & 101 & $44^{\mathrm{c}}$ \\
\hline Macedonia & 150 & 149 & 45 \\
\hline Athens & 101 & 101 & $46^{c}$ \\
\hline Bulgaria & 122 & 122 & $47^{\mathrm{c}}$ \\
\hline Tuscany & 218 & 218 & $48^{\mathrm{c}}$ \\
\hline Sicily & 199 & 199 & $48^{\mathrm{c}}$ \\
\hline Tyrol & 229 & 229 & $17^{\mathrm{c}}$ \\
\hline \multicolumn{4}{|l|}{ Indian Subcontinent } \\
\hline Southern India & 122 & 122 & $49^{c}$ \\
\hline Jat Sikhs & 108 & 108 & $50^{c}$ \\
\hline Jat Haryana & 91 & 91 & $39^{c}$ \\
\hline Pakistan Brahui & 110 & 110 & $51^{\mathrm{c}}$ \\
\hline Pakistan Parsi & 90 & 90 & $51^{\mathrm{c}}$ \\
\hline Pakistan Sindhi & 122 & 122 & $51^{\mathrm{c}}$ \\
\hline
\end{tabular}

${ }^{a}$ Number of individuals surveyed. ${ }^{b}$ Number of haplotypes (the ones without duplications) studied herein. Each haplotype was defined by the combination of alleles at the following loci: DYS19-DYS389I-DYS389II-DYS390-DYS391-DYS392-DYS393. ${ }^{c}$ Data obtained from the Y-chromosome haplotype reference database (YHRD) at http://yhrd.org 


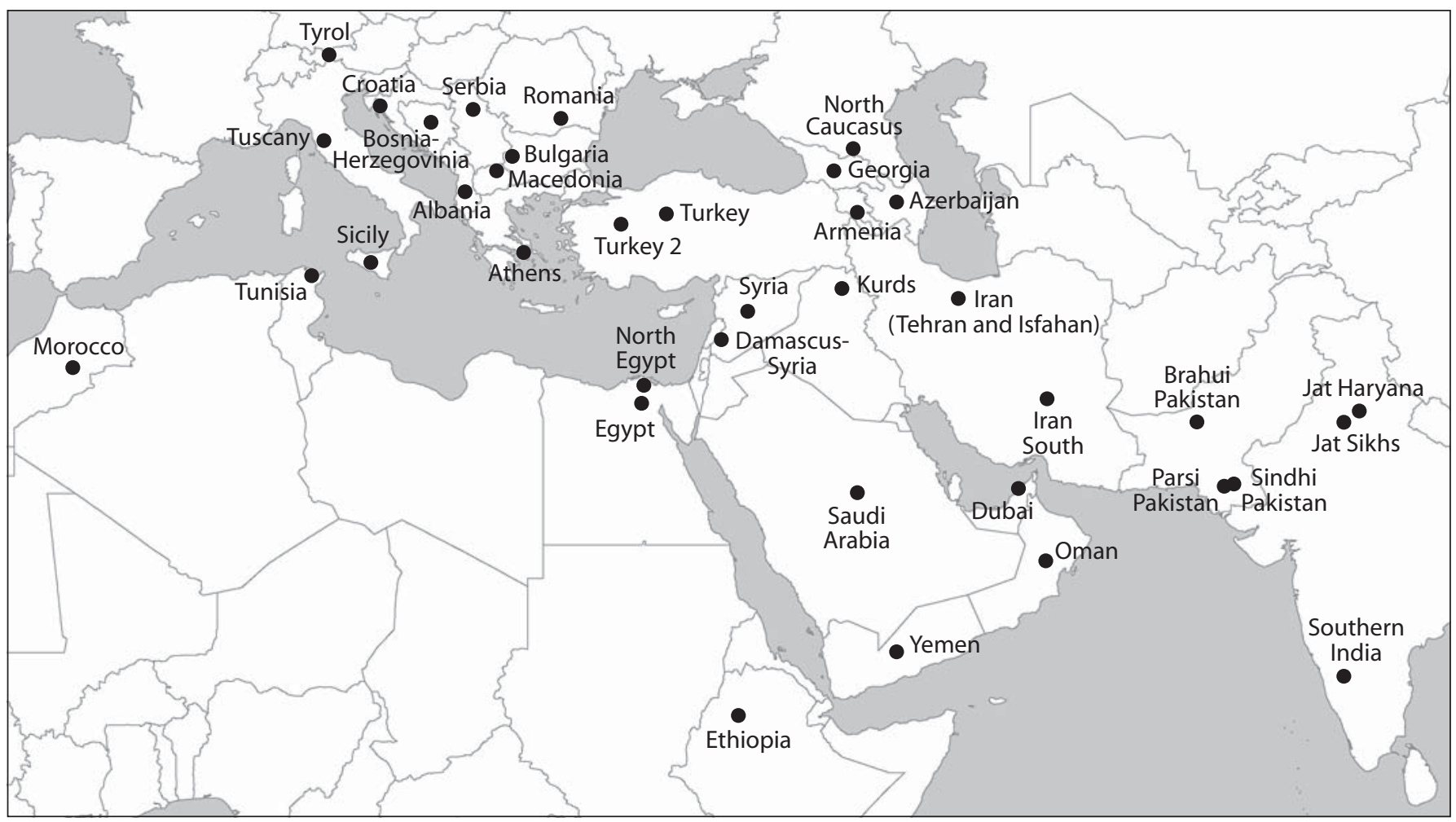

Fig. 1. Approximate location of the 37 samples used in the analyses.

\section{Material and Methods}

\section{Samples and Y-Chromosome STR Typing}

Unrelated male samples were collected from the following populations in the Arabian Peninsula: 217 from Dubai, 99 from Oman, 104 from Yemen and 106 from Saudi Arabia, as well as 104 from South Iran. All the samples were collected from individuals residing in Dubai, along with informed consent and confirmation of genealogic origins two generations back. DNA was extracted using a phenol-chloroform protocol.

The loci screened were: DYS19, DYS389I, DYS389II, DYS390, DYS391, DYS392, DYS393, DYS385, DYS438 and DYS439. Dubai National samples and half of the samples of the other populations were typed using the Y-Plex ${ }^{\mathrm{TM}} 6$ and Y-Plex ${ }^{\mathrm{TM}} 5$ (Reliagene Technologies, New Orleans, La., USA). The remaining of these four populations were typed using the PowerPlex ${ }^{\mathrm{TM}}$ Y system (Promega Corporation). Typing was achieved using an ABI $310 \mathrm{Ge}-$ netic Analyser (AB Applied Biosystems, Foster City, Calif., USA) and allele calls were made by comparison to reference sequenced ladders provided by the manufacturers.

Published data on additional sampled populations that were used for statistical comparison are listed in table 1 and portrayed on the map in figure 1 . The data for 18 of these samples were retrieved from the Y-chromosome haplotype reference database (YHRD). Initially, a sample of $201 \mathrm{Y}$ chromosomes from Somalia [18] was included in the analyses, but it showed to be an extreme outlier in most of the analyses, mainly because of the very high frequency $(75 \%)$, at locus DYS19, of one allele (the 11-repeats allele) that is rare in all the other populations considered here $(<5 \%)$. Consequently, we removed this Somali sample from the analyses. The sample from Ethiopia was also retrieved from the database YHRD but there is no publication reference associated with that population. Note also that many references provided in that database are incorrect, so the references were inferred, although in some cases there is a little difference in sample size between the reference and the sample deposited by the original authors in the database (the ones in the database were used). For the comparisons, the loci DYS385, DYS438 and DYS439 typed in the Arabian Peninsula samples were not considered because the first one is a duplicated marker and the two last ones were not screened in most of the other populations. The repeats of DYS389I were subtracted to the DYS389II, so that its diversity was not considered twice. Chromosomes with duplicated alleles at a locus were removed from the analyses. The haplotypes observed in the five population samples surveyed herein are reported in (online supplementary materials, www.karger.com/doi/10.1159/000210448).

\section{Statistical Analyses}

To infer levels of population structure on the basis of Y-chromosome STR haplotypes, analyses of molecular variance (AMOVA) were performed with the Arlequin software [19]. The number of different alleles observed at all loci was used as a measure of molecular distance between any two STR-defined haplotypes, rather than a measure of size differences between alleles, to obtain 
Table 2. Average Y-chromosome STR gene diversity in the Arabian Peninsula and other geographic groups

\begin{tabular}{lll}
\hline Population or region & $\begin{array}{l}\text { Average gene } \\
\text { diversity }\end{array}$ & Range \\
\hline Dubai & 0.59 & \\
Oman & 0.52 & \\
Saudi Arabia & 0.46 & \\
Yemen & 0.43 & $0.43-0.59$ \\
Arabian Peninsula & $0.50 \pm 0.07$ & $0.53-0.60$ \\
North and East Africa & $0.57 \pm 0.03$ & $0.59-0.62$ \\
Middle East & $0.61 \pm 0.02$ & $0.56-0.62$ \\
Indian Subcontinent & $0.59 \pm 0.02$ & $0.59-0.62$ \\
Caucasus and Turkey & $0.61 \pm 0.01$ & $0.43-0.62$ \\
Southeastern Europe & $0.56 \pm 0.06$ & \\
\hline
\end{tabular}

${ }^{\text {a }}$ Gene diversity averaged over the 7 STR loci for single populations, and gene diversity (and standard deviation) averaged over populations for geographic groups.

$\Phi_{\text {ST }}$ estimates of genetic structure [see 20 for a comparison of the relative performances of $\mathrm{F}_{\mathrm{ST}}$ and $\mathrm{R}_{\mathrm{ST}}$ statistics]. The Arlequin software was also used to estimate Reynolds population pairwise genetic distances [21] based on $\Phi_{\mathrm{ST}}$ values and to assess their statistical significance (10,000 permutations). Matrices of pairwise genetic distances among populations were analysed by means of Multidimensional scaling (MDS) using the NTSYS software [22]. This multivariate method produces a graphical representation of genetic distances between populations. The associated stress value, which is a measure of the goodness-of-fit of the resulting plot to the original distance matrix (the smaller this value, the better the fit), was recorded. Mantel tests, implemented in the NTSYS software, were performed to check for the statistical significance of correlation coefficients between genetic and geographic (greatcircle) distances.

Population genetic structure was also explored through the spatial analysis of molecular variance (SAMOVA) approach [23], which defines groups of populations that are geographically homogeneous and maximally differentiated from one another. This clustering method is based on a simulated annealing procedure that aims to maximize the proportion of the total genetic variation that is due to differences between $k$ groups of populations (the $\Phi_{\mathrm{CT}}$ index, in our case), without any a priori definition of the $k$ groups of populations. Briefly, each sampled population of the geographic space is included in a separate cell of a Voronoi diagram. Then, the populations are randomly distributed in $k$ different groups ( $k$ being specified in input), in keeping with their geographic location (i.e. only geographically adjacent populations can be included in the same group). An AMOVA analysis is performed on this population structure and the resulting $\Phi_{\mathrm{CT}}$ index is kept in memory. Then, one randomly chosen population is moved from its group to another neighbouring group, also chosen at random, and the $\Phi_{\mathrm{CT}}$ index is computed again. This step (i.e. the annealing procedure) is repeated a large number of times $(10,000$ times in our case), and the populations' composition of groups that leads to the highest $\Phi_{\mathrm{CT}}$ value is outputted, together with the values of the associated $\Phi_{\mathrm{SC}}$ and $\Phi_{\mathrm{ST}}$ indices. The analyses were done using a modified version of the SAMOVA 1.0 software that allowed for the use of the number of different alleles ( $\mathrm{F}_{\mathrm{ST}}$-like), instead of the sum of squared differences in allele sizes $\left(\mathrm{R}_{\mathrm{ST}}\right)$, to estimate $\Phi_{\mathrm{CT}}, \Phi_{\mathrm{SC}}$ and $\Phi_{\mathrm{ST}}$ indices. To check that the resulting structure was stable, each of the SAMOVA analyses was repeated 3 times for various numbers of groups ( $k$ between 2 and $10)$. One hundred different initial conditions were tested with each run of the program to ensure that all different ways of grouping populations together were tested. For each run of SAMOVA, if the level of genetic differentiation between population groups $\left(\Phi_{\mathrm{CT}}\right)$ is equal or smaller than that between populations within groups $\left(\Phi_{\mathrm{SC}}\right)$, then the resulting grouping of populations is considered genetically meaningless. If $\Phi_{\mathrm{CT}}$ was found higher than $\Phi_{\mathrm{SC}}$, then the $k$ number of groups were chosen that leads to the highest value of $\Phi_{\mathrm{CT}}$, reflecting the strongest population structure.

\section{Results}

The haplotypes observed in the populations surveyed in this work are provided in online supplementary materials. When considering all the Y-STRs typed, there was a considerable power of haplotype discrimination in the Arabian and Iran populations: $78.6 \%$ in Yemen; $81.1 \%$ in Saudi Arabia; 86.9\% in Dubai; $92.9 \%$ in Oman; and 93.3\% in Iran. The haplotype diversity ranged from 0.989 to 0.998 and on a locus specific level the average gene diversities ranged from 0.480 to 0.670 .

But when comparing with other populations, based on the same Y-STRs, we observed that the within population diversity was generally reduced in the Arabian Peninsula, particularly because of lower average gene diversity in the Saudi Arabian and Yemeni samples (table 2). Locus DYS19 contributed mostly to this observation, with the 13-repeats allele reaching a frequency of more than $70 \%$ in the Saudi Arabian sample and the 14-repeats allele being observed in more than $80 \%$ of Yemenis' Y chromosomes. Loci DYS389-I and DYS392 were also poorly diversified in these populations and to a lesser extent, in Oman as well, but for these loci a very frequent allele was also observed in populations from other regions.

\section{Genetic Structure in the Arabian Peninsula and Adjacent Geographic Regions}

We first considered the 37 populations of table 1 in a single group to estimate the level of genetic differentiation inferred from Y-STRs over the broad geographic region. The global level of population structure (table 3 ) is approximately $7 \%$, with values for individual loci ranging from 3\% (DYS389II) to almost 12\% (DYS393). AMOVA 
Table 3. Levels of genetic structure among 37 populations from the Arabian Peninsula and adjacent geographic regions, inferred from 7 Y-chromosome STRs analyses

\begin{tabular}{lc}
\hline Loci & $\Phi_{\mathrm{ST}}, \%^{\mathrm{a}}$ \\
\hline All & $7.06^{\mathrm{b}}$ \\
DYS19 & $7.14^{\mathrm{c}}$ \\
DYS389I & $4.35^{\mathrm{c}}$ \\
DYS389II & $3.24^{\mathrm{c}}$ \\
DYS390 & $7.80^{\mathrm{c}}$ \\
DYS391 & $6.48^{\mathrm{c}}$ \\
DYS392 & $9.06^{\mathrm{c}}$ \\
DYS393 & $11.58^{\mathrm{c}}$ \\
\hline
\end{tabular}

a All $\Phi_{\mathrm{ST}}$ values are significant $\left(\mathrm{p}<10^{-4}\right)$.

${ }^{\mathrm{b}} \Phi_{\mathrm{ST}}$ value inferred from the frequency distribution of the 7 STR haplotypes weighted by the number of different alleles between haplotypes ( $\mathrm{F}_{\mathrm{ST}}$-like).

$\mathrm{F}_{\mathrm{ST}}$.

${ }^{c}$ Here, the index of population structure is the conventional
Table 4. Levels of population differentiation in the Arabian Peninsula and adjacent regions, inferred from 7-STR haplotypes

\begin{tabular}{lll}
\hline Geographic group & $\begin{array}{l}\text { Number of } \\
\text { populations }\end{array}$ & $\Phi_{\mathrm{ST}}, \%^{\mathrm{a}}$ \\
\hline Arabian Peninsula & 4 & 4.24 \\
North and East Africa & 5 & 4.46 \\
Middle East & 5 & 1.24 \\
Indian Subcontinent & 6 & 7.27 \\
Caucasus and Turkey & 6 & 1.53 \\
Southeastern Europe & 11 & 4.90 \\
\hline
\end{tabular}

${ }^{a} \Phi_{\text {ST }}$ value inferred from the frequency distribution of the 7 STR haplotypes weighted by the number of different alleles between haplotypes $\left(\mathrm{F}_{\mathrm{ST}}\right.$-like). All $\Phi_{\mathrm{ST}}$ values are significant $(\mathrm{p}<$ $\left.10^{-4}\right)$.

Table 5. Levels of differentiation between groups of populations $\left(\Phi_{\mathrm{CT}}\right)$ and between populations within groups ( $\left.\Phi_{\mathrm{SC}}\right)$ among 37 populations, and among a subset of 12 populations from the Arabian Peninsula and adjacent geographic regions, inferred from 7 Y-chromosome STRs. These indices of differentiation are calculated on the structure found by SAMOVA

\begin{tabular}{ccclll}
\hline $\mathrm{k}$ & $\Phi_{\mathrm{CT}}, \%^{\mathrm{a}}$ & $\Phi_{\mathrm{SC}}, \%^{\mathrm{a}}$ & $\mathrm{P}\left(\Phi_{\mathrm{CT}}\right)$ & $\mathrm{P}\left(\Phi_{\mathrm{SC}}\right)$ & Significant group structure $^{\mathrm{a}}$ \\
\hline $\begin{array}{c}37 \text { populations } \\
2\end{array}$ & $\mathbf{8 . 7 8}$ & $\mathbf{6 . 3 6}$ & $<\mathbf{0 . 0 5}$ & $<\mathbf{0 . 0 0 1}$ & [Bosnia Herzegovinian] - [all other populations] \\
3 & 5.14 & 6.70 & $<0.05$ & $<0.001$ & \\
4 & 6.27 & 6.30 & $<0.05$ & $<0.001$ & \\
5 & 3.86 & 5.00 & $<0.001$ & $<0.001$ & \\
6 & 3.37 & 6.35 & $<0.05$ & $<0.001$ & \\
7 & 3.69 & 5.98 & $<0.01$ & $<0.001$ & \\
8 & 2.89 & 5.89 & $<0.05$ & $<0.001$ & \\
9 & 2.97 & 5.03 & $<0.001$ & $<0.001$ & \\
10 & 3.45 & 4.49 & $<0.001$ & $<0.001$ & \\
12 populations & & & & & \\
2 & $\mathbf{5 . 0 7}$ & $\mathbf{2 . 2 5}$ & $<\mathbf{0 . 0 5}$ & $<\mathbf{0 . 0 0 1}$ & [Yemen \& Saudi Arabia] - [all other populations] \\
3 & $\mathbf{4 . 5 4}$ & $\mathbf{1 . 5 0}$ & $<\mathbf{0 . 0 0 1}$ & $<\mathbf{0 . 0 0 1}$ & [Yemen \& Saudi Arabia] - [Ethiopia] - [all other populations] \\
4 & $\mathbf{4 . 2 9}$ & $\mathbf{1 . 5 7}$ & $<\mathbf{0 . 0 1}$ & $<\mathbf{0 . 0 0 1}$ & [Yemen] - [Saudi Arabia] - [Ethiopia] - [all other populations] \\
5 & $\mathbf{3 . 7 8}$ & $\mathbf{1 . 0 5}$ & $<\mathbf{0 . 0 0 1}$ & $<\mathbf{0 . 0 0 1}$ & [Yemen \& Saudi Arabia] - [Ethiopia] - [Egypt \& North Egypt] - \\
& & & & & [Damascus Syria] - [all other populations]
\end{tabular}

${ }^{\text {a }} \Phi_{\mathrm{CT}}$ and $\Phi_{\mathrm{SC}}$ values are shown in bold when $\Phi_{\mathrm{CT}}>\Phi_{\mathrm{SC}}$, and the associated structure of population groups is described (groups separated by brackets).

was also performed for each of the six geographic groups defined in table 4 . The level of genetic structure in the Arabian Peninsula (4.24\%) was comparable to both that of the North and East Africa group (4.46\%) and that of South-eastern Europe (4.90\%). By contrast a weak, al- though still significant, population structure was observed among Middle Eastern populations and in the Caucasus and Turkey group, both below 2\%. The highest level of differentiation characterized the South Asian (Indian subcontinent) group (more than 7\%). 


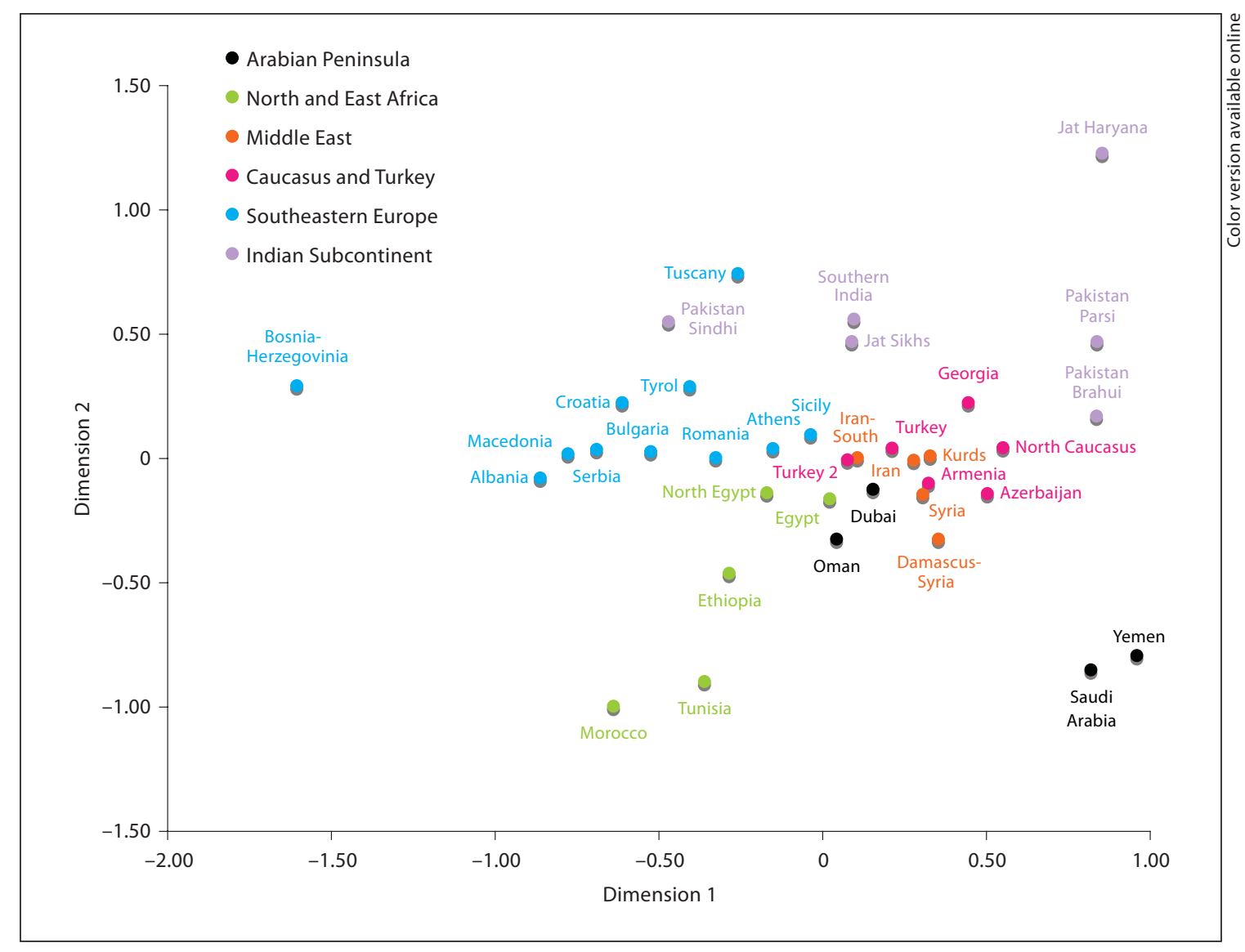

Fig. 2. Multidimensional Scaling Analysis (MDS) of genetic distances among the populations shown in table 1 and figure 1 ; stress value $=0.133$. The populations are highlighted with a color code shown in the caption, that corresponds to the geographic regions listed in table 1 and figure 1.

MDS analysis of the genetic distances showed that populations within a geographic group tend to cluster together, and that three geographic groups radiate, in a centrifugal fashion, in three different directions from the centre of the plot (fig. 2): North and East Africans in one direction, Indians in another direction, and South-eastern Europeans in a third direction. Conversely, populations from Turkey, the Caucasus and the Middle-East were found less separated and located in a central position in the MDS plot. Notably, the populations from the Arabian Peninsula were separated into two groups, with Oman and Dubai occupying a central position, whereas Saudi Arabia and Yemen clearly differentiated towards the periphery of the plot. Thus, a general correspondence with geography was observed and was indeed associated with a positive and significant correlation of genetic and geographic distances $(r=0.42, \mathrm{p}<0.0001)$.
To investigate in greater detail the genetic structure of the populations and the amount of genetic variation due to differences among population groups, the SAMOVA algorithm [23] was applied. Runs were performed so as to search for a number of groups $n$ comprised between 2 and 10 . When the SAMOVA was performed for all 37 populations, only the structure with two groups $(k=2)$ was genetically relevant (table 5). It separated the Bosnia-Herzegovinia sample from a group comprising all other samples $\left(\Phi_{\mathrm{CT}}=0.088, \mathrm{p}<0.05 ; \Phi_{\mathrm{SC}}=0.064, \mathrm{p}<0.001\right)$. With $k>2$, the $\Phi_{\mathrm{SC}}$ index was found always smaller than the $\Phi_{\mathrm{CT}}$ index, indicating that no geographically-homogeneous population groups could be differentiated from others (table 5).

\section{The Arabian Peninsula}

Further analyses were performed focusing on a smaller geographic scale around the Arabian Peninsula. The 


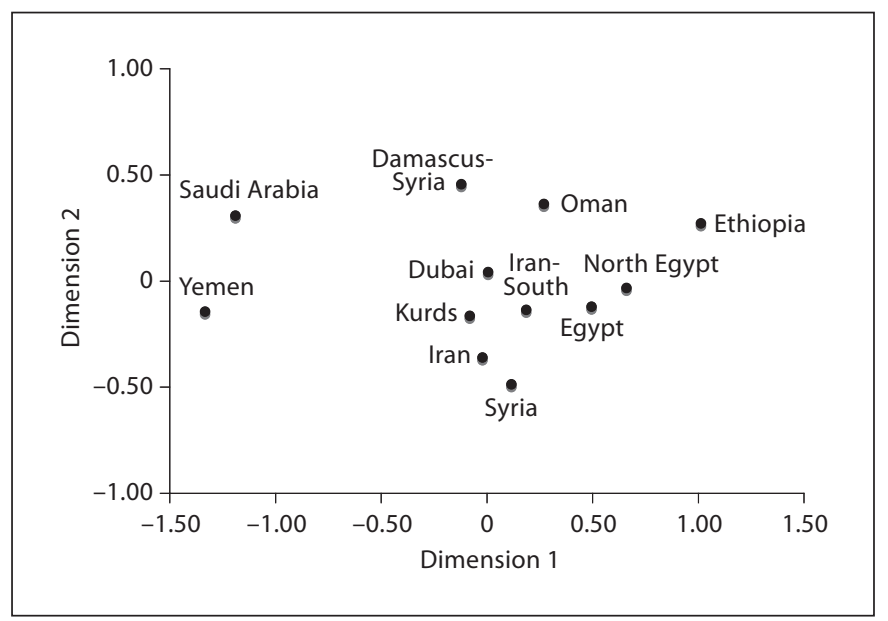

Fig. 3. Multidimensional Scaling Analysis (MDS) of genetic distances among the 12 populations from the Arabian Peninsula, North and East Africa and Middle East groups; stress value = 0.060 .

dataset was restricted to 12 populations: Dubai, Oman, Yemen, Saudi Arabia, North Egypt, Egypt, Ethiopia, Syria, Damascus Syria, Kurds, Iran and Iran South.

The strong differentiation of Saudi Arabians and Yemenis from other populations in the region was confirmed again with an MDS analysis of genetic distances among these 12 populations (fig. 3). Saudi Arabians and Yemenis were located near one another on one side of the plot, whereas all other populations clustered towards the other side. Although significant at the $1 \%$ level, the $\Phi_{\mathrm{ST}}$ value between Saudi Arabians and Yemenis was only $1.4 \%$. Conversely, $\Phi_{\mathrm{ST}}$ values between each of these 2 populations and each of the other two from the Peninsula (Oman and Dubai) ranged from 5 to $7 \%$, as were those with all the Middle Eastern populations, while those with the Egyptians and Ethiopians ranged from 8 to 13\% (all these $\Phi_{\text {ST }}$ values with $\mathrm{p}<0.001$ ).

The differentiation of Yemen and Saudi Arabia was consistent with SAMOVA on the 12 populations' dataset (table 5). Indeed, the strongest population structure (i.e. the largest $\Phi_{\text {СT }}$ value) was obtained when the number of population groups $k$ was 2 , and it significantly separated Yemen and Saudi Arabia on one side and all other populations on the other side $\left(\Phi_{\mathrm{CT}}=0.051, \mathrm{p}<0.05\right.$; $\Phi_{\mathrm{SC}}=$ $0.025, \mathrm{p}<0.001)$. Furthermore, the $\Phi_{\mathrm{CT}}$ value decreased with an increasing number of groups $(k>2)$. With $k=3$, Ethiopia was isolated as a new group $\left(\Phi_{\mathrm{CT}}=0.045\right.$, $\mathrm{p}<$ $\left.0.001 ; \Phi_{\mathrm{SC}}=0.015, \mathrm{p}<0.001\right)$, and when $k=5$, DamascusSyria split from the bulk of remaining populations
$\left(\Phi_{\mathrm{CT}}=0.038, \mathrm{p}<0.001 ; \Phi_{\mathrm{SC}}=0.011, \mathrm{p}<0.001\right)$. These results were consistent with the MDS analysis (fig. 3), in showing that Yemen and Saudi Arabia formed a cluster diverging from all the populations in the region, that is in an area encompassing East Africa, the Levant, the Arabian Peninsula, and extending to Iran, whereas Ethiopia and Damascus-Syria were the most differentiated populations of this second, relatively homogeneous group.

\section{Discussion}

Our analyses of the genetic Y-STR diversity on a broad geographical scale, centred around the Arabian Peninsula, revealed that the genetic structure in the Middle East can be globally described by a pattern of isolation by distance [24]. Indeed, on the basis of genetic distances, populations from the same geographic area tended to cluster together but no regional groups diverged significantly from others. All regional groups of populations were connected with the populations of the Near-East, consistent with the major role of this area as a corridor for human migrations. Focusing on a local scale, two main observations emerged: (1) within the Arabian Peninsula, the Dubai and Oman populations were genetically close as were the Yemen with the Saudi Arabia populations (they were not statistically differentiated at $1 \%$ ) as might be expected for geographic neighbours; (2) the Dubai and Oman samples were not differentiated from the bulk of the other populations, being relatively close to Egyptians, as well as populations from the Middle-East and India. These results support that Y-STRs can be useful in disentangling recent local population structure based on the paternal lineage, corroborating and extending previous evidence from other genetic markers.

The genetic proximity of Oman and Dubai with the Middle-Eastern and Indian populations is indicative of genetic exchange throughout this region. In particular, the closeness between Oman/Dubai and Iran suggests that the Ormuz strait was not a barrier to migrations. Indeed, there is evidence that the Ormuz strait completely disappeared during the last glacial maximum (LGM) around 20,000 years ago, being covered by sand dunes [25], and thus was crossable by early modern humans. In more recent times, there is archaeological and historic evidence indicating a close proximity (i.e., exchange) between populations around the Ormuz strait [26]. There are the shared 'Ubaid type painted pottery (5500-3000 BC) and the Jamdat Nasr type pottery (3000-2500 BC). Terrestrial and maritime routes were established around 
the Ormuz strait along the Magan period (2500-2000 $\mathrm{BC}$ ), the Roman period and the Sasanian dynasty (emerging in $240 \mathrm{AD}$ ). The conversion to Islam of the eastern Arabian coast occurred with the arrival of envoys from the Prophet in $630 \mathrm{AD}$, and from here the Islamic armies launched the conquest of Iran in $637 \mathrm{AD}$.

Some genetic studies have supported the relatedness between populations across the Ormuz strait. Regueiro et al. [27] showed that the Y-chromosome pool of Iranians displayed contributions from both Turkey and Pakistan (although greater for the former), supporting the notion of Persia as a venue for human disseminations. All studies are concordant about the fact that gene flow was stronger from west to east than the opposite, both for Ychromosome and mtDNA [28].

On the other hand, the finding that the genetically close Yemen and Saudi Arabia are relatively isolated within the bulk of Middle-Eastern populations, notwithstanding the genetically weakly structured context, is more difficult to explain. There are several historical and archaeological records indicating a good deal of contact with the western Arabian coast, involving the trade of the local products myrrh and incense. Historically important, the Sabaeans, a federation of Arab tribes in modern Yemen, and the Minaeans, farther north along the caravan route, had a major influence in Ethiopia, from the sixth century $\mathrm{BC}$ till the first century $\mathrm{AD}$, with the fusion of Arab and Ethiopians possibly originating the important Aksum Empire, centred on the Tigre (or Tigrai) plateau. Islamic faith centred in the city of Mecca, an important node in the camel trade between southern Arabia and the Middle East, expanded to most of Arabia before the death of the prophet in 632, and after, at a fast rate to Syria, Iraq and Egypt and, in less than 80 years, to all North Africa and part of Spain.

This genetic isolation of Yemen and Saudi Arabia, as well as of Bedouins (nomadic herders found in all Arabic countries attaining as much as $10 \%$ of the population), from Near Eastern populations was detected previously via Principal Component (PC) analyses of frequency variation of classical genetic markers [26]. Unfortunately, there were no data from UAE and Oman in those studies; but there were results from Kuwait and Kurds. The fourth Principal Component (PC4) of these data shows contact between western Arabia and the rest of Asia but it accounts only for $6.4 \%$ of total variance, thus reflecting a very weak signal of structure for the classical markers.

The Y-STR diversity studies herein revealed that Yemen and Saudi Arabia have less genetic affinity with the African populations, Egypt and Ethiopia, than almost all other sample populations of the region (fig. 3). This is contrary to expectations given their geographic proximity. The data suggest that genetic exchanges were not particularly strong between Yemen/Saudi Arabia and East Africa. Other studies show this general low sub-Saharan genetic input in Arabia, which is less for the male lineage component $(4-7 \%[8,9])$ compared with the female one (39\% [28]). These eastern African populations were the source of slaves to Arabia since the 7th century, by interventions of the Omani Empire and then, in the 16th to 17 th centuries, the Portuguese, and favoured females (domestic and concubines) over males (many imported as eunuchs).

Besides a relative isolation from migration and trading routes, another (not exclusive) hypothesis that could account for the observed genetic differentiation of Saudi Arabia and Yemen could be linked to cultural practices such as male polygamy. Polygyny is expected to reduce the Y-chromosome population effective size and thus contribute to genetic differentiation through drift [29]. This assumption was shown to hold for Arab tribal groups of the Sinai Peninsula that traditionally practiced both polygamy and patrilocal exogamy [30], by comparing Ychromosome genetic diversity with that of mitochondrial DNA. One could speculate that male polygamy was a practice more common in Yemen and Saudi Arabia than in Oman and Dubai. In keeping with this hypothesis, the data herein suggest lower Y-chromosome diversity in the Southern part of the Peninsula (i.e. Saudi Arabia and Yemen), as shown by the gene diversity indices (table 2). However, these estimations are associated with large standard deviations; whether or not these differences are significant between populations will require much larger sample sizes than the ones currently used. Moreover, higher gene diversity is also expected for populations with higher levels of gene exchange, as suggested here for Oman and Dubai. Studies testing the same individuals for autosomal and gender-specific polymorphisms [29, 30] could help to disentangle the effect of geographic isolation from that of marital practices.

Excepting Yemen and Saudi Arabia, a genetic transects between Ethiopia and Iran, via Egypt, is suggested from the Y-STR diversity data. This appears to indicate that gene flow was more likely through Egypt than through the Bab el Mandeb strait. However, this interpretation must be considered with caution. More samples surveyed, in particular from East-Africa, may lend more clarity to the potential migration route(s). Regarding the 'Southern Route' hypothesis [2,3] and extant Y-STR data our analyses do not indicate a large migration flow over 
the Bab el Mandeb strait. Also, since the region is relatively undifferentiated, migration appears to have been frequent over the Bab el Mandeb strait but even more frequent through Egypt. A preference for the Levant Corridor was also inferred by Rowold et al. [31] when focusing in Eurasian and M1 mtDNA lineages exchange between East Africa and Arabian Peninsula/Near East. However their conclusions are still open to debate, since their affirmed M1 exchange via the Horn of Africa was not corroborated by Olivieri et al. [32] who inferred a back to Africa of M1 (or of an ancestor) via the Levant around 40,000 years ago.

The Y-STR diversity analyses conducted herein appear to reflect relatively recent demographic events, as would be expected for such genetic markers. Extended gene flow connecting Africa, South-Eastern Europe and Western Asia throughout the Near-East is reflected in the Y-STR diversity of the region. The Southern part of the Arabian Peninsula does not appear to be a major migration route as it appears more genetically isolated. In contrast, the Northern part of the Arabian Peninsula seems much more integrated to the bulk of Near-Eastern populations, which is consistent with the network of cultural and commercial exchange that characterised this dynamic geographic region.

\section{Acknowledgements}

This work was supported by Dubai Police and the Project PTDC/ANT/66275/2006, funded by Fundação para a Ciência e a Tecnologia. IPATIMUP is supported by Programa Operacional Ciência, Tecnologia e Inovação (POCTI), Quadro Comunitario de Apoio III. M.C. and E.P. are partly supported by a Swiss National Foundation grant No. 3100-112651 to A. Sanchez-Mazas.

\section{Links to the Software Used in This Study}

Arlequin and SAMOVA can be downloaded from Laurent Excoffier's Computational and Molecular Population Genetics Lab, University of Bern, Switzerland (http://cmpg.unibe.ch/software).

The modified algorithm of SAMOVA will be included in a future release of the software (upon request to Mathias Currat).

\section{References}

1 Torroni A, Achilli A, Macaulay V, Richards M, Bandelt HJ: Harvesting the fruit of the human mtDNA tree. Trends Genet 2006;22: 339-345.

-2 Macaulay V, Hill C, Achilli A, Rengo C, Clarke D, Meehan W, Blackburn J, Semino O, Scozzari R, Cruciani F, Taha A, Shaari NK, Raja JM, Ismail P, Zainuddin Z, Goodwin W, Bulbeck D, Bandelt HJ, Oppenheimer S, Torroni A, Richards M: Single, rapid coastal settlement of Asia revealed by analysis of complete mitochondrial genomes. Science 2005;308:1034-1036.

-3 Thangaraj K, Chaubey G, Kivisild T, Reddy AG, Singh VK, Rasalkar AA, Singh L: Reconstructing the origin of Andaman Islanders. Science 2005;308:996.

-4 Abu-Amero KK, Gonzalez AM, Larruga JM, Bosley TM, Cabrera VM: Eurasian and African mitochondrial DNA influences in the Saudi Arabian population. BMC Evol Biol 2007;7:32.

-5 Cerny V, Mulligan CJ, Ridl J, Zaloudkova M, Edens CM, Hajek M, Pereira L: Regional differences in the distribution of the sub-Saharan, West Eurasian, and South Asian mtDNA lineages in Yemen. Am J Phys Anthropol 2008;136:128-137.
-6 Kivisild T, Reidla M, Metspalu E, Rosa A, Brehm A, Pennarun E, Parik J, Geberhiwot T, Usanga E, Villems R: Ethiopian mitochondrial DNA heritage: tracking gene flow across and around the gate of tears. Am J Hum Genet 2004;75:752-770

7 Alshamali F, Brandstätter A, Zimmermann B, Parson W: Mitochondrial DNA control region variation in Dubai, United Arab Emirates. Forensic Sci Int: Genet 2008:e9-e10.

8 Richards M, Rengo C, Cruciani F, Gratrix F, Wilson JF, Scozzari R, Macaulay V, Torroni A: Extensive female-mediated gene flow from sub-Saharan Africa into near eastern Arab populations. Am J Hum Genet 2003;72: 1058-1064.

-9 Luis JR, Rowold DJ, Regueiro M, Caeiro B, Cinnioglu C, Roseman C, Underhill PA, Cavalli-Sforza LL, Herrera RJ: The Levant versus the Horn of Africa: evidence for bidirectional corridors of human migrations. Am J Hum Genet 2004;74:532-544.

10 Arredi B, Poloni ES, Paracchini S, Zerjal T, Fathallah DM, Makrelouf M, Pascali VL, Novelletto A, Tyler-Smith C: A predominantly neolithic origin for Y-chromosomal DNA variation in North Africa. Am J Hum Genet 2004;75:338-345.

-11 Pereira L, Dupanloup I, Rosser ZH, Jobling MA, Barbujani G: Y-chromosome mismatch distributions in Europe. Mol Biol Evol 2001; 18:1259-1271.
12 Dupanloup I, Pereira L, Bertorelle G, Calafell F, Prata MJ, Amorim A, Barbujani G: A recent shift from polygyny to monogamy in humans is suggested by the analysis of worldwide Y-chromosome diversity. J Mol Evol 2003;57:85-97.

13 Currat M, Excoffier L: The effect of the Neolithic expansion on European molecular diversity. Proc Biol Sci 2005;272:679-688.

14 Pereira L, Gusmao L, Alves C, Amorim A, Prata MJ: Bantu and European Y-lineages in Sub-Saharan Africa. Ann Hum Genet 2002; 66:369-378.

15 Roewer L, Croucher PJ, Willuweit S, Lu TT, Kayser M, Lessig R, de Knijff P, Jobling MA, Tyler-Smith C, Krawczak M: Signature of recent historical events in the European Ychromosomal STR haplotype distribution. Hum Genet 2005;116:279-291.

16 Kayser M, Lao O, Anslinger K, Augustin C, Bargel G, Edelmann J, Elias S, Heinrich M, Henke J, Henke L, Hohoff C, Illing A, Jonkisz A, Kuzniar P, Lebioda A, Lessig R, Lewicki S, Maciejewska A, Monies DM, Pawlowski R, Poetsch M, Schmid D, Schmidt U, Schneider PM, Stradmann-Bellinghausen B, Szibor R, Wegener R, Wozniak M, Zoledziewska M, Roewer L, Dobosz T, Ploski R: Significant genetic differentiation between Poland and Germany follows present-day political borders, as revealed by Y-chromosome analysis. Hum Genet 2005;117:428-443. 
17 Roewer L, Krawczak M, Willuweit S, Nagy $\mathrm{M}$, Alves C, Amorim A, Anslinger K, Augustin C, Betz A, Bosch E, Caglia A, Carracedo A, Corach D, Dekairelle AF, Dobosz T, Dupuy BM, Furedi S, Gehrig C, Gusmao L, Henke J, Henke L, Hidding M, Hohoff C, Hoste B, Jobling MA, Kargel HJ, de Knijff P, Lessig R, Liebeherr E, Lorente M, MartinezJarreta B, Nievas P, Nowak M, Parson W, Pascali VL, Penacino G, Ploski R, Rolf B, Sala A, Schmidt U, Schmitt C, Schneider PM, Szibor R, Teifel-Greding J, Kayser M: Online reference database of European Y-chromosomal short tandem repeat (STR) haplotypes. Forensic Sci Int 2001;118:106-113.

- 18 Hallenberg C, Simonsen B, Sanchez J, Morling N: Y-chromosome STR haplotypes in Somalis. Forensic Sci Int 2005; 151:317-321.

$>19$ Excoffier L, Laval G, Schneider S: Arlequin ver. 3.0: An integrated software package for population genetics data analysis. Evolutionary Bioinformatics Online 2005;1:4750.

20 Balloux F, Goudet J: Statistical properties of population differentiation estimators under stepwise mutation in a finite island model. Mol Ecol 2002;11:771-783.

-21 Reynolds J, Weir BS, Cockerham CC: Estimation of the Coancestry Coefficient: Basis for a Short-Term Genetic Distance. Genetics 1983;105:767-779.

22 Rohlf FJ: NTSYSpc: Numerical Taxonomy System, ver. 2.10. InSetauket, NY, Exeter Publishing, Ltd, 2007.

-23 Dupanloup I, Schneider S, Excoffier L: A simulated annealing approach to define the genetic structure of populations. Mol Ecol 2002;11:2571-2581.

24 Wright S: Isolation by Distance. Genetics 1943;28:114-138.

-25 Glennie KW, Singhvi AK: Event stratigraphy, paleoenvironment and chronology of SE Arabian deserts. Quat Sci Rev 2002;21: 853-869.

26 Cavalli-Sforza LL, Menozi P, Piazza A: The History and Geography of Human Genes. Princeton, Princeton University Press, 1994.

-27 Regueiro M, Cadenas AM, Gayden T, Underhill PA, Herrera RJ: Iran: tricontinental nexus for Y-chromosome driven migration. Hum Hered 2006;61:132-143.

-28 Quintana-Murci L, Chaix R, Wells RS, Behar DM, Sayar H, Scozzari R, Rengo C, Al-Zahery N, Semino O, Santachiara-Benerecetti AS, Coppa A, Ayub Q, Mohyuddin A, TylerSmith C, Qasim Mehdi S, Torroni A, McElreavey $\mathrm{K}$ : Where west meets east: the complex mtDNA landscape of the southwest and Central Asian corridor. Am J Hum Genet 2004;74:827-845
29 Seielstad MT, Minch E, Cavalli-Sforza LL: Genetic evidence for a higher female migration rate in humans. Nat Genet 1998;20:278 280.

30 Salem AH, Badr FM, Gaballah MF, Pääbo S The genetics of traditional living: Y-chromosomal and mitochondrial lineages in the $\mathrm{Si}$ nai Peninsula. Am J Hum Genet 1996;59: 741-743.

31 Rowold DJ, Luis JR, Terreros MC, Herrera RJ: Mitochondrial DNA geneflow indicates preferred usage of the Levant Corridor over the Horn of Africa passageway. J Hum Genet 2007;52:436-447.

$\$ 32$ Olivieri A, Achilli A, Pala M, Battaglia V, Fornarino S, Al-Zahery N, Scozzari R, Cruciani F, Behar DM, Dugoujon JM, Coudray C, Santachiara-Benerecetti AS, Semino O, Bandelt HJ, Torroni A: The mtDNA legacy of the Levantine early Upper Palaeolithic in Africa. Science 2006;314:1767-1770.

-33 Quintana-Murci L, Bigham A, Rouba H, Barakat A, McElreavey K, Hammer M: Ychromosomal STR haplotypes in Berber and Arabic-speaking populations from Morocco. Forensic Sci Int 2004;140:113-115.

34 Manni F, Leonardi P, Barakat A, Rouba H, Heyer E, Klintschar M, McElreavey K, Quintana-Murci L: Y-chromosome analysis in Egypt suggests a genetic regional continuity in Northeastern Africa. Hum Biol 2002;74: 645-658.

35 Abdin L, Dewa K, Rand S, Hohoff C, Brinkmann B: Analysis of 13 Y-chromosomal STRs in an Arab population sample from Syria. Prog Forensic Genet 2003;1239:319321.

-36 Brinkmann C, Forster P, Schürenkamp M, Horst J, Rolf B, Brinkmann B: Human Ychromosomal STR haplotypes in a Kurdish population sample. Int J Legal Med 1999;112: 181-183.

37 Nasidze I, Schadlich H, Stoneking M: Haplotypes from the Caucasus, Turkey and Iran for nine Y-STR loci. Forensic Sci Int 2003; 137:85-93.

38 Cakir AH, Celebioglu A, Yardimci E: Y-STR haplotypes in Central Anatolia region of Turkey. Forensic Sci Int 2004;144:59-64.

-39 Henke J, Henke L, Chatthopadhyay P, Kayser M, Dulmer M, Cleef S, Poche H, Felske-Zech $\mathrm{H}$ : Application of Y-chromosomal STR haplotypes to forensic genetics. Croat Med J 2001;42:292-297.
40 Barbarii LE, Rolf B, Dermengiu D: Y-chromosomal STR haplotypes in a Romanian population sample. Int J Legal Med 2003;117: 312-315.

41 Klaric IM, Lauc LB, Pericic M, Janicijevic B, Terzic R, Colak I, Kvesic A, Rudan P: Evaluation of Y-STR variation in Bosnian and Herzegovinian population. Forensic Sci Int 2005; 154:252-256.

42 Lauc LB, Pericic M, Klaric IM, Sijacki A, Popovic D, Janicijevic B, Rudan P: Y chromosome STR polymorphisms in a Serbian population sample. Forensic Sci Int 2005; 150:97-101.

43 Lovrecic L, Ristic S, Brajenovic B, Kapovic M, Peterlin B: Human Y-specific STR haplotypes in the Western Croatian population sample. Forensic Sci Int 2005;149:257-261.

44 Robino C, Gino S, Ricci U, Grignani P, Previdere C, Torre C: Y-chromosomal STR haplotypes in an Albanian population sample. Forensic Sci Int 2002;129:128-130.

45 Spiroski M, Arsov T, Kruger C, Willuweit S, Roewer L: Y-chromosomal STR haplotypes in Macedonian population samples. Forensic Sci Int 2005;148:69-73.

46 Parreira KS, Lareu MV, Sanchez-Diz P, Skitsa I, Carracedo A: DNA typing of short tandem repeat loci on Y-chromosome of Greek population. Forensic Sci Int 2002;126:261264

-47 Zaharova B, Andonova S, Gilissen A, Cassiman JJ, Decorte R, Kremensky I: Y-chromosomal STR haplotypes in three major population groups in Bulgaria. Forensic Sci Int 2001;124:182-186.

48 Presciuttini S, Caglia A, Alu M, Asmundo A, Buscemi L, Caenazzo L, Carnevali E, Carra E, De Battisti Z, De Stefano F, Domenici R, Piccinini A, Resta N, Ricci U, Pascali VL: Ychromosome haplotypes in Italy: the GEFI collaborative database. Forensic Sci Int 2001; 122:184-188.

49 Frank WE, Ralph HC, Tahir MA: Y chromosome STR haplotypes and allele frequencies in a southern Indian male population. J Forensic Sci 2008;53:248-251.

50 Nagy M, Henke L, Henke J, Chatthopadhyay PK, Volgyi A, Zalan A, Peterman O, Bernasovska J, Pamjav H: Searching for the origin of Romanies: Slovakian Romani, Jats of Haryana and Jat Sikhs Y-STR data in comparison with different Romani populations. Forensic Sci Int 2007;169:19-26.

51 Mohyuddin A, Ayub Q, Qamar R, Zerjal T, Helgason A, Mehdi SQ, Tyler-Smith C: Ychromosomal STR haplotypes in Pakistani populations. Forensic Sci Int 2001;118:141146 . 